Int. J. Electrochem. Sci., 11 (2016) $4399-4409$

\title{
Synthesis of Schiff Base Surfactants and Their Corrosion Inhibition Effect on Tubing Steel in Deep Oil Wells
}

\author{
Changjin Wang ${ }^{1, *}$, Yinpeng $\mathrm{Li}^{1}$ and Wen Zhou ${ }^{2 *}$ \\ ${ }^{1}$ Department of petrochemical, Northeast Petroleum University at Qinhuangdao, No. 550 West of \\ Hebei Rd, Haigang, Qinhuangdao, Hebei, 066004, P.R. China \\ 2 The Second Clinical College of Guangzhou University of Chinese Medicine (Guangdong Provincial \\ Academy of Chinese Medical Sciences), 55 Neihuanxi Road, Guangzhou, 510006, China \\ *E-mail: changjinwang_01@126.com; xtunwen@163.com
}

doi: $10.20964 / 2016.06 .26$

Received: 29 February 2016 / Accepted: 23 March 2016 / Published: 4 May 2016

\begin{abstract}
In this work, we synthesized a series of Schiff base surfactants using chemical route. The properties of the surfactants including critical micelle concentration, maximum surface excess, minimum surface area and surface tension were determined. Results indicate the properties of the surfactants are highly related to their chain length. The corrosion inhibition effect of the Schiff base surfactants was evaluated on deep oil well tubing steel. Electrochemical impedance spectroscopy, polarization, polarization and weight loss experiments were carried out. Surfactant molecules were well absorbed on the carbon steel surface and can be described using Langmuir adsorption isotherm. The effect of several parameters were studied and discussed.
\end{abstract}

Keywords: Schiff base surfactant; Corrosion; Deep oil well; Tubing steel; Surface tension

\section{$\underline{\text { FULL TEXT }}$}

(C) 2016 The Authors. Published by ESG (www.electrochemsci.org). This article is an open access article distributed under the terms and conditions of the Creative Commons Attribution license (http://creativecommons.org/licenses/by/4.0/). 